\title{
Por uma ciência da imprevisão
}

\section{Por una ciencia de la imprevisión}

https://doi.org/10.34112/2317-0972a2021V39n81p79-97

Diego Winck Esteves ${ }^{1}$

Máximo Daniel Lamela Adó ${ }^{2}$

\section{PARA UMA CIÊNCIA}

Se quer seguir-me, narro-lhe - não os resultados de uma pesquisa, que almejaria qualquer tipo de conclusão, mas a recorrente prospecção, mais forte do que eu, acerca de uma suposta ciência, a qual, por meio de experimentos, especulo por uma constituição possível. São, desde então, 18 meses intensos - em verdade esta é a ponta de um iceberg, o topo de um período bem mais extenso da minha vida a especular no entorno desta ideia (ainda que, durante anos eu não estivesse consciente desta excursão).

Tal ideia, digo-lhe: a de que existe uma dimensão improvisada sob as aparências que constituem nossa vida. Desta suposição emerge uma inquietação da qual decorre minha obsessão: instituir uma ciência capaz de estudar esses processos imprevistos (não vistos a priori, para os quais, portanto, não temos a posse de referências consistentes, a não ser por transposições heterogêneas) e improváveis (pois, sem modelo e sem matriz de causa-efeito, que aqui não se aplica, nada se pode provar - no sentido de comprovação —, nos resta assim provar — no sentido

1. Universidade Federal do Rio Grande do Sul, RS, Brasil.

2. Universidade Federal do Rio Grande do Sul - UFRGS, RS, Brasil. 
de experimentar - e, por essa via, especular). A consequência disso seria que tal ciência demandaria um método extático, por assim dizer. Mas há um empecilho que tem me afligido sempre que considero essa empreitada - e digo sem dó: o humano! Disso decorre um paradoxo: como posso eu, humanamente constituído, me agenciar com as tecnologias de uma ciência não humana? O problema é mais complexo, você vê: a ciência é constituída humanamente, bem como nossos aparatos tecnológicos - ora, pois?

A questão então gira no entorno - ao menos minha prospecção chegou até aqui - não da negação do humanismo ocidental, sobre o qual se constitui a ciência, mas de criar condições para uma agência científica, digamos, ante-humana (e não anti-humana).

Mas veja onde me leva o ânimo... acabei por esquecer-me, num misto entre ansiedade, indignação e alegria, das anotações que deveriam guiar este relato (e devo logo alertá-lo que ele se constitui no ato mesmo da escrita, como dito entre um gole e outro de café, nas entrelinhas do olhar silencioso ante um transeunte que corta a paisagem ao acaso, tendo sempre a presença destas anotações em meu caderno azul, que miro vez ou outra para não encontrar-me demasiadamente perdido; anotações que não são nada mais do que intuições que por ora compartilho, com a esperança de que possa encontrar cumplicidade).

Passo, assim às anotações:

Primeiro, que estou especulando acerca de uma espécie de Ciência Nômade do Improviso. Segundo, que esta ideia ganha força com as proposições do "Tratado de Nomadologia”, de Deleuze e Guattari — donde o fato de qualquer semelhança não ser mera coincidência; logo, não só os conceitos de Máquina de Guerra, Nômade e Ciência Menor são importantes, pois outros, mesmo que aqui não relatados, são imprescindíveis aos exercícios de pensamento nos quais estou engajado; destaco os conceitos de devir, multiplicidade, heterogeneidade, pré-individual, ante-eu e a noção de corpo, tomada na esteira do pensamento de Spinoza e Nietzsche.

Permita-me, antes, mais uma reflexão (não quero denunciar lamúrias, mas intuo ser o contexto indispensável para percorrermos juntos este relato - para estarmos ambientados, por assim dizer): nas tentativas fracassadas, sobre as quais esse relato colhe os resíduos, sempre que o ânimo me estimulava o pensamento. Quando do encontro desta ideia - a de uma ciência, a partir dos conceitos filosóficos -, eu me sentia, de contragolpe, paralisado, percebia nitidamente minha energia escoar para o espaço no qual eu estava imbuído; logo, não queria escrever (não podia, não tinha 
forças!), sob o risco de humanizar, de dar um rosto para o que não tem, de dizer o mesmo de sempre em outras palavras de agora, de fazer um esboço sobre uma figura já dada, porém, esquecida. Além do mais, e peço que releve o tom confessional, não teria eu mais do que ínfimas improváveis chances de propor tal Ciência Nômade do Improviso: a matéria que detinha para compor era consideravelmente insuficiente para construir algo que parasse em pé (o que dizer sobre caminhar... sobre dançar!); mas veja como me contradigo, pois andar não seria uma coisa humana? E dançar? Ou, poderia haver (ou há?) uma ciência animal?

O fato é que eu não sabia o que fazer, só pensava, desejava uma redução de pensamentos (do ponto de vista de uma racionalidade); supunha um pensar movido por tais infra improvisações da vida, das quais a forma é residual (e o humano é uma forma, apesar das replicações maneiristas). Noutros momentos, quando uma raiva de súbito me esquentava o sangue, queria, em vão, arrancar o humano de mim! No segundo seguinte, ponderava, racionalmente (veja a ironia!), se não seria o caso de ser a própria dimensão humana desejando aniquilar-se, uma vez que o animal que porventura habitasse em meu corpo, por suposição, sequer notaria essa abstração que é o humanismo.

Num dia, já exausto deste labirinto no qual titubeava entre me oferecer um mérito hercúleo, ou uma ingenuidade infantil, encontrei um texto antigo que, de surpresa, me arrebatou mais uma vez: com ele, sobre uma espécie de transposição compositiva, ou conjunção disjuntiva, consegui, por fim, dar a ver ao menos um rascunho de um mapa que, quiçá, poderá nos levar a um território no qual colheremos, em futuro próximo, a matéria necessária para modular essa ciência de fins práticos - para que ela desnude as coisas de todas as imagens que se projetam sobre elas, com tecnologias que nos possibilitem perceber, e com sorte compreender, as improvisações vitais das quais são feitas as coisas em si!

Trata-se do conto "O espelho", de Guimarães Rosa. Narro-lhe, então, o que vem sendo motivo e ao mesmo tempo objeto da especulação. Faço-o pondo em jogo fragmentos de "O espelho" e do "Tratado de Nomadologia"; observe, contudo, que esses fragmentos, por mais estranho que isso possa parecer, são meus próprios pensamentos, que só puderam ganhar forma no encontro com os textos e se encaixaram perfeitamente nos excertos que, se naqueles corpos tinham um sentido, aqui tomam outros - e, mais do que isso, são as próprias peças que possibilitam a maquinação do pensar, o que não é, com efeito, de minha propriedade (nem as peças, nem a maquinação em si).

Pois bem, não me leve a mal, não é que me sinta incapaz, mas se é o caso de ser a vida que nos improvisa o tempo todo (se emergimos do Nada, por improvisações 
compositivas não humanas, eis o ponto da minha interrogação), só nos cabe uma aliança coletiva, uma vez que, somente eventualmente na história, um ou outro de nós consegue olhar para fora do palco no qual somos o teatro e assim sacar, ou intuir, índices do modus operandi da dramaturgia por detrás das manifestações nas quais somos imagens, tanto quanto uma coisa detém as suas, e as palavras. Minha hipótese é, assim, mais impertinente: a de que, ao olhar para esse "fora" (que pode muito bem ser um dentro), nada veríamos que tivesse um rosto, senão uma maquinação regida pelo acaso, uma complexa articulação de microimprovisações; mas feitas do quê? De Nada?

A título de organização deste relato, dividi tal prospecção em cinco pontos; após, deixo as consequências a você, cuja correspondência espero possa lançar mais luz nesse breu (no qual pouco vejo, mas muito percebo; e, sem visão suficiente, pouco posso fazer com a claridade excessiva das palavras). Dos pontos, então: a questão, empecilhos a priori, experimentos, dificuldades encontradas, devaneios conclusivos.

\section{A QUeSTÃo}

O objeto desta Ciência da Imprevisão (outro nome possível para Ciência Nômade do Improviso) é O informe: ou seja, o que é da ordem do sensível (só percebido via afecções); se visto do ponto de vista da física: é energia, movimento; logo, mesmo que seja evidente, é preciso reforçar, é a-significante. Daí o paroxismo desta ciência: ela estuda o que não tem sentido e, somente nestes termos: tudo que passa para o âmbito da linguagem já não lhe interessa e está fora do seu domínio! Assim, jamais se esqueça: "é de fenômenos sutis que estamos tratando" (ROSA, 2005, p. 114).

Façamos uma distinção em quatro tópicos, de modo a dar a ver "as características de uma tal ciência excêntrica” (DELEUZE; GUATTARI, 1997, p. 25). Portanto,

seriam as seguintes: 1) Teria inicialmente um modelo hidráulico, ao invés de uma teoria dos sólidos, que considera os flú́dos como um caso particular; com efeito, o atomismo antigo é indissociável dos fluxos, o fluxo é a realidade mesma ou a consistência. 2) É um modelo de devir e heterogeneidade que se opõe ao estável, ao eterno, ao idêntico, ao constante. É um "paradoxo", fazer do próprio devir um modelo, e não mais o caráter segundo de uma cópia. [...] 3) Já não se vai da reta a suas paralelas, num escoamento lamelar ou laminar, mas da declinação curvilínea à formação das espirais e turbilhões sobre um plano inclinado. [...] O modelo é turbilhonar, num espaço aberto onde as coisas-fluxo se distribuem, em vez de distribuir num espaço fechado 
para coisas lineares e sólidas. É a diferença entre um espaço liso (vetorial, projetivo ou topológico) e um espaço estriado (métrico): num caso, "ocupa-se o espaço sem medi-lo", no outro, "mede-se o espaço a fim de ocupá-lo". 4) Por último, o modelo é problemático, e não mais teoremático: as figuras só são consideradas em função das afeç̧ões que lhes acontecem, secções, ablações, adjunções, projeções. [...] Há aí toda sorte de deformações, transmutações, passagens ao limite, operações onde cada figura designa um "acontecimento" muito mais que uma essência. (DELEUZE; GUATTARI, 1997, p. 26, grifos dos autores)

\section{EMPECILHOS A PRIORI}

Essa ciência precisa, portanto, lidar primeiro com algumas resistências inerentes ao humano que nos constitui: se é impossível destituir sua presença (do humano), pretende-se ao menos desviar-se ao pô-lo em jogo. Pois, a começar que os

[...] próprios olhos, de cada um de nós, padecem viciação de origem, defeitos com que cresceram. [...] Os olhos, por enquanto, são a porta do engano; duvide deles, dos seus, não de mim. Ah, meu amigo, a espécie humana peleja para impor ao latente mundo um pouco de rotina e lógica, mas algo ou alguém de tudo faz frincha para rir-se da gente... E então? (ROSA, 2005, p. 114)

Contudo, se por um lado temos um corpo organizado, ou melhor, forças que produzem a organização dos corpos, donde desponta uma visão sedenta por encontrar sentidos, padrões, ritmos e formas, corpo que assim se habitua ou busca habituar-se, esse mesmo corpo é atravessado por forças outras, e é por elas desterritorializado; assim,

[...] os sentimentos são arrancados à interioridade de um "sujeito" para serem violentamente projetados num meio de pura exterioridade que lhes comunica uma velocidade inverossímil, uma força de catapulta: amor ou ódio já não são em absoluto sentimentos, mas afectos. E esses afectos são outros tantos devir-mulher, devir-animal do guerreiro (o urso, as cadelas). Os afectos atravessam o corpo como flechas, são armas de guerra. Velocidade de desterritorialização do afecto. (DELEUZE; GUATTARI, 1997, p. 18, grifo dos autores). 
Pois vejamos: se os afectos são armas de guerra, no sentido que, ao atravessar o sujeito que nos constitui - deveras humano e, assim, se não um inimigo, ao menos uma espécie de oponente que resiste ao nosso método científico experimental —, precisamos criar condições para nos expor, para sermos afectados tanto quanto possível e devir-outro (mas que seja um devir minoritário); esse devir-outro pode significar um encontro com um eu submerso sobre o humano, como um pré-individual: um devir-animal guerreiro, podemos considerar que aí em nosso corpo resida — ou que a partir dele, com outras matérias-forças, possa se compor e transformar. Assim, desde o problema da visão, sobre nossa imagem refletida no espelho (no gesto cotidiano de mirar-se), adentrando aos poucos na mais sutil percepção de si, procurar-se (à espreita de uma versão imprevista de si, aquela que a vida improvisa a cada instante e que buscamos encontrar, via experimentos): "Desde aí, comecei a procurar-me - ao eu por detrás de mim - à tona dos espelhos, em sua lisa, funda lâmina, em seu lume frio. Isso, que eu saiba, antes ninguém tentara. Quem se olha em espelho, o faz partindo de preconceito afetivo, de um mais ou menos falaz pressuposto" (ROSA, 2005, p. 116).

\section{EXPERIMENTOS}

Assim passamos a relatar os experimentos aos quais adentramos e os associamos a essa ciência que é objeto de nossa especulação: pois lidar com a imprevisão, ao menos de início, demanda esforçados experimentos extáticos, que nos desloquem, por milímetros que seja, da nossa condição humana. Cabe considerar que, nesse momento, eu estava já tomado pela possibilidade de um devir-animal guerreiro: primeiro, pela suposição humana do guerreiro, composta sobre a imagem do animal; segundo, porque o guerreiro necessita de um desapego, de uma tensão descontraída para empreender um golpe preciso, ou o desvio de um ataque improvável; ele não pode se agarrar a uma imagem de si, humana, familiar, sentimental, pois ela lhe instituiria um medo da morte, e esse medo lhe retiraria a atenção, reduzindo a eficácia de suas habilidades - que passariam a buscar a sobrevivência, quando elas precisam da ação imediata, desprovida de qualquer objetivo externo a si, externo à ação em si, pois a pré-ocupação lhe reduziria a velocidade.

Tendo essas possibilidades em mente, passei a experimentar, sobre as intempéries do dia, ao acaso, com golpes precisos (ao menos com esse objetivo), algo que pudesse me servir de índice para provar o que, constatado, seria o solo inabalável desta ciência: que eu mesmo era imprevisto para mim! Ora, pois, conquistado este 
feito, tendo-o como um fato dado, toda a realidade aparente seria colocada em dúvida, tão logo o observador emergisse a cada instante, do Nada, em cada mirada, e de maneira imprevista. Assim,

operava com toda a sorte de astúcias: o rapidíssimo relance, os golpes de esguelha, a longa obliquidade apurada, as contra-surpresas, a finta de pálpebras, a tocaia com a luz de-repente acesa, os ângulos variados incessantemente. Sobretudo, uma inabalável paciência. (ROSA, 2005, p. 116)

Estou afirmando, como pode ver, o estudo de coisas-fluxo: daí resulta a principal dificuldade, pois que a ciência, em geral, necessita de um objeto de estudo, e uma coisa-fluxo, embora coisa, é, sobretudo, fluxo - ou seja, materialmente falando, um não objeto; eu me faço entender? Vejamos:

Husserl fala de uma protogeometria que se dirigiria a essências morfologicamente vagas, isto é, vagabundas ou nômades. Essas essências se distinguiriam das coisas sensíveis, mas igualmente das essências ideais, régias, imperiais. A ciência que dela trataria, a protogeometria, seria ela mesma vaga, no sentido de vagabunda: nem inexata como as coisas sensíveis, nem exata como as essências ideais, porém anexata e contudo rigorosa. (DELEUZE; GUATTARI, 1997, p. 34, grifos dos autores)

Por suposto, para tratar desta Ciência da Imprevisão, desde a essência das coisas, que seriam, em suas primeiras aparições ou no nível molecular, nômades, vagas, vagabundas, rebatemos nossa ideia de uma ciência excêntrica sobre a imagem da Ciência Moderna, a ciência do Estado, a ciência do Humano: se estou, por essa via, me colocando numa espécie de combate com o humano, é em favor do corpo - o corpo habitado pela ideia, pelo modo humano de ser, digamos, mas que é anterior e posterior ao humano. Estudar essas essências vagas - noutras palavras, o informe que nos constitui e ganha forma regido pelo antropocentrismo característico da modernidade, feito à sua imagem - é condição para perceber o corpo em sua complexidade: o ante-humano! Coisas-corpo ou corpos-coisa: "dir-se-ia que as essências vagas extraem das coisas uma determinação que é mais que a coisidade, é a da corporeidade, e que talvez até implique um espírito do corpo" (DELEUZE; GUATTARI, 1997, p. 35).

É preciso não ver o que está ali, no sentido do que revemos por suposição, e ver o que não está, no sentido de que não vemos por não ser esperado. Paradoxal? 
Por suposto, os não sentidos são matéria nobre (ou não matéria) do método que estamos a inventar! Quando ao espelho, então, "era principalmente no modus de focar, na visão parcialmente alheada, que eu tinha de agilitar-me: olhar não-vendo" (ROSA, 2005, p. 117). É importante que "saiba que eu perseguia uma realidade experimental, não uma hipótese imaginária” (ROSA, 2005, p. 117). O que buscamos são rastros, pelo caráter sutil do nosso "objeto". Assim:

Já não se trata exatamente de extrair constantes a partir de variáveis, porém de colocar as próprias variáveis em estado de variação contínua. Se há ainda equações, são adequações, inequações, equações diferenciais irredutíveis à forma algébrica, e inseparáveis por sua vez de uma intuição sensível da variação. Captam ou determinam singularidades da matéria em vez de constituir uma forma geral. Operam individuações por acontecimentos ou hecceidades, e não por "objeto" como composto de matéria e de forma; as essências vagas não são senão hecceidades. (DELEUZE; GUATTARI, I997, p. 38, grifo dos autores).

\section{Dificuldades ENCONTRADAS}

Essas dificuldades não são senão o reaparecimento insistente do que definimos como empecilhos a priori: nosso olho que vê em excesso, salta de um cabeção pesado, que mira e diz: é isso, é isso, é isso! Agimos, ademais, pautados por uma moral (parte significativa do peso desta cabeça), e não tarda que nos questionemos, insensíveis aos avanços feitos em nossos experimentos, sobre os sentidos dessa busca, de quão absurda ela é: mas é isso, meu amigo, é isso a existência, A-B-S-U-R-D-A! Ela não te ouve, por isso não responde: tal como o espelho, que reflete o que pensamos ver, ouvimos o que dizemos: mas entre a fala e o eco esquecemo-nos da origem do som. Queremos tudo controlar: a forma é consequência da nossa expressão, do que expressamos, não há existências prévias à nossa ação no mundo: há, contudo, coisas que ali estão, claro, mas, supondo que a existência não se dá alheia aos sentidos no coexistir, é o humano que faz as combinações.

Projetava assim essas questões no entorno da imagem de mim mesmo, no espelho, por uma reflexão cada vez mais lacunar, por traços imprevistos, detalhes não antes incluídos na minha feição, não suficiente sempre estarem ali. 
Prossegui. Já aí, porém, decidindo-me tratar simultaneamente as outras componentes, contingentes e ilusivas. Assim, o elemento hereditário - as parecenças com pais e avós que são também, em nossos rostos, um lastro evolutivo residual. Ah, meu amigo, nem no ovo o pinto está intacto. E, em seguida, o que se deveria ao contágio das paixões, manifestas ou latentes, o que ressaltava das desordenadas pressões psicológicas transitórias. E, ainda, o que em nossas caras, materializa ideias e sugestões de outrem; e os efêmeros interesses, sem sequência nem antecedência, sem conexões nem fundura. (ROSA, 2005, p. 118).

Segui nesses experimentos. Passo então para o quarto e último ponto, mas sobre ele lhe peço uma mente de principiante, como se não tivesse a mínima ideia da medida do possível — que, por suposto, eu diria, não sabemos.

\section{Devaneios conclusivos}

Em dado momento de meus experimentos, como por esgotamento, ou habilidade adquirida, conquistei um modo de olhar que, por pequenos instantes, não via; não posso convencê-lo, nem a mim, de não se tratar de um efeito fisiológico, da vista cansada, ou mesmo da pressão sanguínea reduzida e seus efeitos de embotamento mental; mas, lembremos que não estamos operando sobre o binômio causa-efeito, donde o que nos importa são os acontecimentos: é disso que trata a Ciência da Imprevisão, de acontecimentos puros, no instante em que surgem do Nada, e que aparecem sem sentido. Assim o fiz.

Tanto dito que, partindo para uma figura gradualmente simplificada, despojara-me, ao termo, até a total desfigura. E a terrível conclusão: não haveria em mim uma existência central, pessoal, autônoma? Seria eu um... des-almado? Então, o que se me fingia de um suposto $e u$, não era mais que, sobre a persistência do animal, um pouco de herança, de soltos instintos, energia passional estranha, um entrecruzar-se de influências, e tudo o mais que na impermanência se indefine? Diziam-me isso os raios luminosos e a face vazia do espelho - com rigorosa infidelidade. E, seria assim, com todos? Seríamos não mais que as crianças - o espírito do viver não passando de ímpetos espasmódicos, relampejos entre miragens: a esperança e a memória. (ROSA, 2005, p. 119). 
Logo, veja que esses experimentos denotam a possibilidade de desdobrar o que pensávamos (mas talvez a manifestação até aqui não tenha ficado clara o suficiente): trata-se de considerar que sob um espaço estriado (o da cidade, por exemplo), há um espaço liso, tal como há, sob a face, uma massa, somente uma massa modulada, e sua consequente topologia: é a nossa tendência adquirida por ver buracos e depois tubos, e depois medidas e órgãos e funções etc., que produz o espaço estriado sobre uma pele contínua, ainda que feita de dobras — mas uma dobra não é uma repartição.

Um campo, um espaço liso heterogêneo, esposa um tipo muito particular de multiplicidades: as multiplicidades não métricas, acentradas, rizomáticas, que ocupam o espaço sem "medi-lo", e que só se pode explorar "avançando progressivamente". Não respondem à condição visual de poderem ser observadas desde um ponto no espaço exterior a elas: por exemplo, o sistema dos sons, ou mesmo das cores. (DELEUZE; GUATTARI, 1997, p. 40, grifo dos autores).

Não podendo ser observadas essas multiplicidades, de um ponto exterior, é preciso, pois, entrar no jogo, sentir na pele, ocupar-se do espaço: não se trata de ver, mas de perceber, notar pela pele - que de alguma maneira registra esses acontecimentos, como se anotasse os efeitos dessas afecções.

Agora podemos ver com um pouco mais de clareza - veja como sua presença me motiva! - que essa ciência que propomos, a Ciência da Imprevisão, ou uma Ciência Nômade do Improviso, não pode, nem quer, instituir-se de um modo definitivo, não quer inserir-se no quadro contemporâneo das ciências (a não ser que seja no limiar onde esse quadro perde a forma, se encontra com outras coisas...): seria, então o caso de definirmos como uma Filosofia da Imprevisão? Tampouco importa, estamos numa zona onde conceitos e funções se confundem, e podem ganhar facilmente - sem perda de força para o pensar — o estatuto de ficção: mas não podemos esquecer que seguimos uma realidade experimental, e não uma abstração imaginária! De todo modo, é importante considerar o "fato de que, nas ciências ambulantes ou nômades, a ciência não está destinada a tomar um poder e nem sequer um desenvolvimento autônomos" (DELEUZE; GUATTARI, 1997, p. 44).

Desse modo, nossa ciência funciona por alianças, uma vez que não pode resolver os problemas que inventa, pois seu interesse está em inventar outros problemas ali onde aquele parece se esgotar; precisa assim das ciências de estado; precisa, por consequência, justamente do que colocamos em xeque: é evidente que precedemos 
de uma dimensão ante-humana para essa Ciência da Imprevisão, mas avançamos ao humano e aos artifícios da linguagem para tratar de soluções.

No campo da interação das duas ciências, as ciências ambulantes contentam-se em inventar problemas, cuja solução remeteria a todo um conjunto de atividades coletivas e não científicas, mas cuja solução científica depende, ao contrário, da ciência régia, e da maneira pela qual esta ciência de início transformou o problema, incluindo-o em seu aparelho teoremático e em sua organização do trabalho. Um pouco como a intuição e a inteligência segundo Bergson, onde só a inteligência possui os meios científicos para resolver formalmente os problemas que a intuição coloca, mas que esta se contentaria em confiar às atividades qualitativas de uma humanidade que seguisse a matéria... (DELEUZE; GUATTARI, 1997, p. 45, grifos dos autores).

Você conhece minha relação com a docência e, na articulação desta com a pesquisa, ao considerar que, de certo modo, uma não se faz sem a outra - quer seja pela potência presumida no seguir pesquisando matérias para o ensino, quer seja ao tomar o espaço de educação como uma aliança de pesquisas (o que me interessa sobremaneira) ou, no mínimo, que o docente que repete o que sabe só pode assim proceder porque outrora pesquisou. Digo isso para lembrar que, embora em busca de uma ciência, a questão central que guia esta excursão está no entorno de uma educação: ou seja, de instituir uma ciência na qual, por meio do estudo de um "objeto", estude-se a si mesmo, pois destituído do lugar de sujeito do conhecimento, onde o eu passa a ser matéria também de estudo, da pesquisa - e por meio desta alquimia, uma mistura de elementos da ciência, filosofia e arte, passa a constituir os saberes.

Logo, para todos os efeitos, a Ciência da Imprevisão, tendo em vista a pesquisa-docência, opera pela intuição: resiste, em princípio, aos artífices da inteligência, busca seguir as forças e se afectar por elas. Combate o humano em si, resistindo a ele e, por meio dele, ao signo: não os nega, mas é ativa para com as forças, em detrimento das formas e dos significados; é nômade, ambulante, itinerante, vagabunda. $\mathrm{Na}$ articulação desta intuição com a inteligência, no translado (e no limiar sempre presente) do ante-humano ao humano, uma forma é dada ao material, uma matéria é composta com as coisas-fluxos: esse processo tenho chamado de Poéticas da Notação. Todavia, para essa poética deter força, o pesquisador-docente precisa primeiro da imprevisão experimental, para esquecer de si, jogar-se na pesquisa, no labirinto, ludibriar suas pretensas certezas, fissurar a logosfera e contornar o abismo. 
Significa entrelaçar, com as afecções desses processos a-significantes, numa transposição poética, sua matéria de estudo: que então é arquivada, organizada, ficando a postos para futuras composições inventivas.

Sobre essa maneira poética de lidar com os indícios coletados dos experimentos, com o que resta das experimentações extáticas do qual lhe falava, poderá avaliar por conta própria, num texto que posso lhe apresentar oportunamente. Mas antes, gostaria de lhe apontar alguns desdobramentos destes estudos.

Seguindo nossa excursão, de Deleuze e Guattari, pelo interesse numa Ciência Menor, que possa seguir os fluxos, que possa seguir, inclusive, e no extremo, o intangível - o que não significa, ininteligível —, chegamos a Bergson, mais precisamente pela relação entre intuição e inteligência, apontada no excerto do Tratado de Nomadologia, o qual utilizamos ao final da anotação anterior. Passamos, então, no nosso próprio exercício de seguir, pelos rastros de um filósofo ao outro, aos problemas que nossa própria intuição coloca e ${ }^{3}$ para os quais a inteligência e seus artifícios formalizam respostas possíveis.

Faremos então algumas anotações sobre a introdução do livro A evolução criadora, as quais desdobram nossa ideia acerca de uma Ciência Nômade do Improviso, ou Ciência da Imprevisão. Sobre a inteligência, então:

Veremos que a inteligência humana se sente em casa enquanto for deixada entre os objetos inertes, mais especialmente entre os sólidos, nos quais nossa ação encontra seu ponto de apoio e nossa indústria seus instrumentos de trabalho, veremos que nossos conceitos foram formados à imagem dos sólidos, que nossa 1ógica é sobretudo a 1ógica dos sólidos, e que, por isso mesmo, nossa inteligência triunfa na geometria, na qual se revela o parentesco do pensamento 1ógico com a matéria inerte e na qual basta a inteligência seguir seu movimento natural, após o mais leve contato possível com a experiência, para ir de descoberta em descoberta com a certeza de que a experiência segue logo atrás dela e lhe dará invariavelmente razão. (BERGSON, 2005, p. 9).

Seguindo, acerca da totalidade da vida, para além dos sólidos ou da nossa lógica dos sólidos, Bergson continua (2005, p. 10): "nenhuma das categorias de nosso pensamento, unidade, multiplicidade, causalidade mecânica, finalidade inteligente etc., se aplica de forma exata às coisas da vida". Na sequência, aponta uma crítica ao que, nos 
termos de Deleuze, aparece enquanto pensamento da representação, e, logo, afirma a contemplação do improvável que emerge nos avanços científicos: critica os enquadramentos efetuados pelo humano - ao analisar o que é vivo -, os quais, apesar do esforço, não se mostram adequados ao que se pretende enquadrar. E, ademais, ao concluir por certo modo de proceder da vida, não obstante, descobre-se que esta opera de uma forma que não havíamos pensado. Adiante, numa crítica à filosofia evolucionista da época (demasiado humana, diríamos), mas da qual podemos encontrar indícios no pensamento presente, em nosso caso - da Educação -, Bergson (2005, p. 11) afirma:

Começara por nos mostrar na inteligência um efeito local da evolução, uma pequena luz, talvez acidental, que ilumina o vai-e-vem dos seres vivos na estreita passagem franqueada a sua ação: e eis que, de repente, esquecendo o que acaba de nos dizer, transforma essa lanterna manobrada no fundo de um subterrâneo em um Sol que iluminaria o mundo. Intrepidamente, apenas com as forças do pensamento conceitual, lança-se na reconstrução ideal de todas as coisas, até mesmo da vida.

Disso ele descreve que, após muito tempo de orgulho, esse pensamento, em seu decurso, ao ver a lógica encontrar diversos obstáculos e contradizer-se, acaba por recuar e postar-se sobre um "excesso de humildade", ao concluir: "a essência das coisas nos escapa e sempre nos escapará, movemo-nos em meio a relações, o absoluto não é de nossa alçada, detenhamo-nos frente ao Incognoscível", e, portanto, "não é mais a própria realidade, diz ela, que irá recompor, mas apenas uma imitação do real, ou antes uma imagem simbólica” (BERGSON, 2005, p. 11).

Bergson, contudo, não está de acordo com essa postura, com uma conclusão de que a realidade só pode ser simbolizada, ou que a mimese seria nosso recurso derradeiro frente a algo que seria inacessível: ora, pois, ser incognoscível não significa inacessível, uma vez que não é somente pela cognição que acessamos a "essência" das coisas; e daí sua conclusão, como veremos, pela intuição.

Seguimos sua argumentação: a de que a ação não pode agir no irreal, logo nosso corpo foi constituído num corpo a corpo com o real; e nossa forma intelectual, assim, se moldou em reciprocidade com seu entorno material; ele diz, contudo, que até poderia aceitar que um ser que nasce para especular, imaginar, sonhar, inventasse sua própria realidade, mas resta que detemos uma inteligência que age sobre as coisas; logo, é uma inteligência (logo, um corpo, digo eu) que toca algo do absoluto; ele afirma, então, que não teríamos colocado em dúvida esse valor absoluto de nosso 
conhecimento, se a filosofia não tivesse apontado contradições em nossa especulação. Mas, tal como sugere, estas contradições são postas em cena a partir de um conhecimento intelectual não orientado para este "absoluto", e sim para a "matéria inerte" - e as supostas contradições destas especulações no entorno do absoluto seriam um falso problema, nos termos do que Deleuze nos apresenta no primeiro capítulo do livro Bergsonismo. E, então, pergunta Bergson (2005, p. 12), e tal pergunta pode ser tomada como um fragmento precioso para nossa Ciência da Imprevisão:

Caberia então renunciar a aprofundar a natureza da vida? Caberia ater-se à representação mecanicista que o entendimento sempre nos dará dela, representação necessariamente artificial e simbólica, uma vez que restringe a atividade total da vida à forma de uma certa atividade humana, a qual não é mais que uma manifestação parcial e local da vida, um efeito ou um resíduo da operação vital?

Com efeito, sugere que a inteligência precisa fusionar com outras capacidades da consciência (e pergunto: ou inconscientes?); que os humanos, demasiadamente centrados no intelecto, não conseguem se desvencilhar das amarras exteriores e colocam, então, em questão que essa fusão pode produzir "uma consciência co-extensiva à vida e capaz de, voltando-se bruscamente contra o impulso vital que sente atrás de si, obter dele uma visão integral, ainda que sem dúvida evanescente?” (BERGSON, 2005, p. 13).

Ademais, Bergson segue compondo um paralelo entre teoria do conhecimento e teoria da vida, para as quais faremos aqui, sob nossa responsabilidade, uma relação entre a Ciência de Estado e a Ciência Nômade; e assim, também, entre inteligência e intuição (ou ainda outras faculdades). Propomos que estas duas teorias trabalhem juntas. Vejamos:

O que equivale a dizer que a teoria do conhecimento e a teoria da vida nos parecem inseparáveis uma da outra. Uma teoria da vida que não vem acompanhada de uma crítica do conhecimento é fadada a aceitar, tais e quais, os conceitos que o entendimento põe a sua disposição: não pode fazer mais que encerrar os fatos, por bem ou por mal, em quadros preexistentes que ela considera como definitivos. Obtém assim um simbolismo cômodo, talvez mesmo necessário à ciência positiva, mas não uma visão direta de seu objeto. Por outro lado, uma teoria do conhecimento que não reinsere a inteligência na evolução geral da vida não nos ensinará nem como os quadros do conhecimento se constituíram, 
nem como podemos ampliá-los ou ultrapassá-los. É preciso que essas duas investigações, teoria do conhecimento e teoria da vida, se encontrem e, por um processo circular, se impulsionem uma a outra indefinidamente. (BERGSON, 2005, p. 14).

Por aqui encerro, antes que a energia se esgote, antes que o excesso de pensar faça-me pesar. Quero dizer-lhe, para me despedir, que não só sua correspondência aqui é imprescindível, no sentido de que este diálogo me anima o pensamento, como ela também é notável, enquanto um destaque ao exercício do pensar-dizer, como uma espécie de reserva ao pensamento: ora, pois, por aí percebo como algumas elucubrações podem lhe parecer confusas, quando me recordo o quanto sei que você não sabe e, ao recordar, me pergunto pelo que sei. $\mathrm{O}$ retorno indefinido e vertiginoso entre o que penso saber e o pensar sobre o que sei, como vê, é condição para esgotar o excesso de certeza: é desumano esquecer.

\section{REFERÊNCIAS}

BERGSON, Henri. A evolução criadora. Tradução Bento Prado Neto. São Paulo: Martins Fontes, 2005. DELEUZE, Gilles; GUATTARI, Félix. Mil Platôs, v. 5. Tradução de Peter Pál Pelbart e Janice Caiafa.

São Paulo: Editora 34, 1997.

ROSA, João Guimarães. Primeiras Estórias. Rio de Janeiro: Nova Fronteira, 2005.

\section{SOBRE OS AUTORES}

Diego Winck Esteves. Graduado em Educação Física, licenciatura plena, pela Universidade de Santa Cruz do Sul-UNISC; Mestre em Educação pela Universidade Federal do Rio Grande do Sul - UFRGS; artista de circo, dança e performance. E-mail:winckesteves@gmail.com.

Máximo Daniel Lamela Adó. Professor Adjunto no Departamento de Ensino e Currículo - DEC da Faculdade de Educação - FACED-UFRGS e Professor permanente no Programa de Pós-graduação em Educação - PPGEDU-UFRGS. Atua no Eixo temático: Cultura, currículo e sociedade e integra a Linha de Pesquisa Filosofias da Diferença e Educação, com a Temática individual: Poéticas da diferença e Educação. Doutor em Educação pela UFRGS. Mestre em Literatura (Teoria literária) e Licenciado em Ciências Sociais pela UFSC.É Líder do Grupo 
de Pesquisa POÏEIN - Microscopias. Educação. Imanência; coordena o Grupo de Estudos AtEdPo- Ateliê de Educação Potencial e participa da Rede de Pesquisa Escrileituras da diferença em Filosofia-Educação. Realizou estágio pós-doutoral em Educação na FACED-UFRGS em 2014 e 2015 com Bolsa PDJ do CNPQ com supervisão da Profa. Dra. Sandra Mara Corazza e foi integrante do Grupo de pesquisa: DIF - artistagens, fabulações, variações - PPGEDU/FACED/UFRGS entre 2009 e 2021.

E-mail: maximo.lamela@ufrgs.br.

Recebido em 10 de outubro de 2019 e aprovado em 22 de dezembro de 2020. 